\title{
Invasive Stratified Mucin-producing Carcinoma (ISMC) of the Uterine Cervix: Clinicopathological and Molecular Characteristics With Special Emphasis on the First Description of Consistent Programmed Death-ligand 1 (PD-L1) Over-expression
}

\author{
SANGJOON CHOI ${ }^{1}$, SO-WOON KIM ${ }^{2}$ and HYUN-SOO KIM ${ }^{1}$ \\ ${ }^{1}$ Department of Pathology and Translational Genomics, Samsung Medical Center, \\ Sungkyunkwan University School of Medicine, Seoul, Republic of Korea; \\ ${ }^{2}$ Department of Pathology, Kyung Hee University Hospital, \\ Kyung Hee University College of Medicine, Seoul, Republic of Korea
}

\begin{abstract}
Background/Aim: Invasive stratified mucinproducing carcinoma (ISMC) of the uterine cervix has been reported to be more aggressive than other subtypes of endocervical adenocarcinoma. We investigated the clinicopathological and molecular characteristics of eight ISMCs. Patients and Methods: We reviewed the electronic medical records and pathology slides of eight patients with ISMC and conducted programmed death-ligand 1 (PD-L1) immunostaining and targeted sequencing. Results: The patients were between 31 and 54 years. Six tumors were pure ISMCs, and two showed co-existing squamous cell carcinoma and usual-type endocervical adenocarcinoma. Lymph node metastases were detected in three cases. Three patients developed distant metastases to the adnexa, lungs, inguinal lymph nodes, and small intestine. Two patients experienced disease progression, and three developed postoperative local recurrences. All tumors showed PD-LI
\end{abstract}

This article is freely accessible online.

Correspondence to: Hyun-Soo Kim, Department of Pathology and Translational Genomics, Samsung Medical Center, Sungkyunkwan University School of Medicine, 81, Irwon-ro, Gangnam-gu, Seoul 06351, Republic of Korea. Tel: +82 234101243, Fax: +82 234142831,e-mail: hyun-soo.kim@samsung.com; So-Woon Kim, Department of Pathology, Kyung Hee University Hospital, Kyung Hee University College of Medicine, 26, Kyungheedae-ro, Dongdaemun-gu, Seoul 02447, Republic of Korea. Tel: +82 29588732, Fax: +82 29588744, e-mail: sowoonkim86@gmail.com

Key Words: Uterus, cervix, invasive stratified mucin-producing carcinoma, programmed death-ligand 1 . over-expression, with a mean combined positive score of 73.8 (range=30-100). One tumor harbored erb-b2 receptor tyrosine kinase 2 amplification. Conclusion: ISMC of the uterine cervix exhibits a high risk of recurrence, metastasis, and resistance to chemoradiation therapy. PD-L1 overexpression was consistently observed in all ISMCs. This finding raises the possibility that patients with ISMC may benefit from PD-L1 immunotherapy.

Stratified mucin-producing intraepithelial lesion (SMILE) is a newly described premalignant lesion of the uterine cervix. This lesion is believed to arise in the embryonic or reserve cells in the transformation zone. In addition to cervical highgrade squamous intraepithelial lesion (HSIL) and adenocarcinoma in situ (AIS), the well-known premalignant intraepithelial lesions, SMILE is associated with high-risk human papillomavirus (HPV) infection (1). This uncommon lesion is histologically characterized with stratified columnar epithelial cells possessing intracytoplasmic mucin throughout the entire epithelial thickness (1), and is classified as a variant of AIS in the 2014 World Health Organization Classification of Tumours of Female Genital Tumours (2). HSIL and AIS often co-exist with SMILE, and squamous cell carcinoma and usual-type endocervical adenocarcinoma are associated with $10-50 \%$ of SMILE cases $(1,3,4)$. In 2016 , Lastra et al. (5) described a distinctive subtype of invasive endocervical adenocarcinoma exhibiting morphological features similar to those of SMILE as an invasive stratified mucin-producing carcinoma (ISMC) or invasive SMILE. ISMC comprises approximately $10 \%$ of endocervical adenocarcinoma cases and less than $1 \%$ of all cervical carcinoma cases. It is the third most common subtype of 
endocervical adenocarcinoma after usual-type (48\%) and gastric-type (23\%) endocervical adenocarcinomas (3).

Few studies have reported on the clinical aspects of ISMC. ISMC is known to be more aggressive than other histological subtypes of endocervical adenocarcinoma and is associated with frequent recurrences and metastases (6). A recent large-scale cohort study also documented that patients with ISMC had higher rates of lymph node metastasis, local recurrence, and distant metastasis than those with other HPVassociated endocervical adenocarcinomas (7). However, given its rarity, the clinicopathological characteristics and outcomes of patients with ISMC are not clearly understood. Moreover, no clinical practice guidelines for surgical treatment and postoperative chemotherapeutic strategies have been established for ISMC.

In recent years, we have encountered several cases of ISMC of the uterine cervix that initiated a comprehensive review of our archival cases. In this study, we investigated the clinicopathological characteristics and ancillary test results of cervical ISMC. In particular, we evaluated the immunohistochemical expression of programmed deathligand 1 (PD-L1) in cervical ISMC cases. Comprehensive clinicopathological and molecular analyses of these cases will expand our knowledge regarding the clinical features, histological features, immunophenotypes, and genetic characteristics of cervical ISMC.

\section{Patients and Methods}

Case selection. This study was approved by the Institutional Review Board of Samsung Medical Center (approval number: 2020-07-062; approval date: November 6, 2020). The cases were selected from the computerized archival files of the Samsung Medical Center (Seoul, Republic of Korea). During the three-year study period from July 2018 to June 2020, eight patients were diagnosed with ISMC of the uterine cervix. Clinical information, including patient's age at diagnosis, previous gynecological history, presenting symptoms, magnetic resonance imaging (MRI) findings, surgical and postoperative treatment, postoperative recurrence and metastasis, follow-up data, and current status, were obtained from the electronic medical records.

Slide review. Two board-certified gynecological pathologists (S.C. and H.-S.K.) thoroughly examined all available hematoxylin and eosin-stained slides using light microscopy. We collected pathological information, including HPV status, coexisting pathological lesions, greatest dimension and invasion depth of the tumor, lymphovascular space invasion (LVSI), extension to the vagina and parametrium, metastasis to the adnexa, lymph node, and peritoneum, and International Federation of Gynecology and Obstetrics (FIGO) stage (8). We chose the most representative slides for immunohistochemical staining and targeted sequencing.

Immunohistochemical staining. Immunostaining was performed using an automated immunostainer (Ventana BenchMark XT, Ventana Medical Systems, Tucson, AZ, USA) (9-19). After antigen retrieval, 4- $\mu$ m-thick, formalin-fixed, paraffin-embedded slices were incubated with primary antibodies, including p16 (prediluted, clone E6H4, Ventana Medical Systems), p40 (1:100, polyclonal, Biocare Medical, Concord, CA, USA), carcinoembryonic antigen (CEA; 1:200, clone II-7, Dako, Glostrup, Denmark), erb-b2 (prediluted, clone 4B5, Ventana Medical Systems), and PD-L1 (prediluted, clone 22C3, Agilent Technologies, Santa Clara, CA, USA). After chromogenic visualization, the slices were counterstained with hematoxylin. Appropriate positive and negative controls were concurrently stained to validate the staining method. Endometrial serous carcinoma (for p16), cervical squamous cell carcinoma (for p40 and PD-L1), gastric adenocarcinoma (for erb-b2), and colonic adenocarcinoma (for CEA) were used as positive controls. Negative controls were prepared by substituting primary antibodies with nonimmune serum, resulting in no detectable staining. The p16 expression pattern was interpreted as block-positive if $\mathrm{p} 16$ expression was horizontally continuous and strong, and involved nuclear or nuclear plus cytoplasmic staining. All other p16 immunostaining patterns, described as focal nuclear staining or wispy, blob-like, puddled, or scattered cytoplasmic staining, were interpreted as patchy positive $(9,20-25)$. For p40 and CEA expression evaluation, nuclear and cytoplasmic staining with a moderate-to-strong intensity in the nucleus was interpreted as positive expression. Positive staining was considered diffuse if at least $50 \%$ of tumor cells were immunoreactive, or was deemed as focal if fewer than $50 \%$ of the cells were stained $(9,20-22,24,26$, 27). c-erb-b2 immunostaining was interpreted as positive when $\geq 10 \%$ of tumor cells displayed strong complete membranous staining, following the guidance on c-erbB2 testing and scoring of gastric adenocarcinoma (28). PD-L1 expression was determined using the combined positive score (CPS) interpretation guideline (29), which is the number of PD-L1-stained cells (viable tumor cells, lymphocytes, and macrophages) divided by the total number of viable tumor cells, multiplied by 100 . A minimum of 100 viable tumor cells was considered adequate for evaluating PD-L1 positivity. For tumor cells, partial or complete membranous staining at any intensity was regarded as positive expression. Membranous and/or cytoplasmic staining at any intensity was regarded as positive for tumor-associated immune cells.

Targeted sequencing. DNA and RNA were isolated from $10-\mu \mathrm{m}-$ thick slices of formalin-fixed, paraffin-embedded tumor tissues using a sterile 26-gauge needle and the RecoverAll Multi-Sample RNA/DNA Isolation Workflow station (Thermo Fisher Scientific, Waltham, MA, USA). The tissues obtained by manual microdissection were subjected to DNA and RNA extraction for library preparation. Normal tissues were obtained from the adjacent non-neoplastic areas. DNA and RNA were quantified using a Qubit 2.0 Fluorometer (Thermo Fisher Scientific). DNA libraries were prepared as previously described $(30,31)$ from $20 \mathrm{ng}$ of DNA per sample using an Ion AmpliSeq Library Kit 2.0 (Thermo Fisher Scientific) and Oncomine Comprehensive Assay (OCA) v1 panel (Thermo Fisher Scientific) $(31,32)$. RNA libraries were generated from $15 \mathrm{ng}$ of RNA per sample using the Ion AmpliSeq RNA Library Kit (Thermo Fisher Scientific). Libraries were quantified using the Ion Library Universal Quantification Kit (Thermo Fisher Scientific). The OCA v1 panel (Thermo Fisher Scientific) included 143 genes, of which 73 were interrogated for mutational hotspots. In addition, 26 tumor suppressor genes were interrogated for all exons. This panel could detect copy number variations (CNVs) in 
49 genes and fusion drivers in 22 genes (33). A $60 \mathrm{pmol} / \mathrm{l}$ pool of DNA and RNA libraries at a ratio of $4: 1$ was used to prepare the templated ion sphere particles (Thermo Fisher Scientific). Sequencing was performed using the Ion $540 \mathrm{Kit}-\mathrm{Chef}$ (Thermo Fisher Scientific) and Ion S5 system (Thermo Fisher Scientific). Sequencing data of approximately $200 \mathrm{bp}$ reads were generated after 500 flow runs.

Bioinformatics and data analysis pipelines. Sequencing data were analyzed using Torrent Suite Software v5.2.2 (Thermo Fisher Scientific). This workflow was created by adding a custom hotspot browser extensible data file to report mutations of interest and a custom CNV baseline (described below) using the manufacturer's default workflow as previously described $(30,31)$. The pipeline included signaling processing, base calling, quality score assignment, adapter trimming, read mapping to the human genome assembly GRCh37, quality control of mapping, coverage analysis with down-sampling, and variant calling. The variants were identified using the Torrent Variant Caller plug-in and Ion Reporter Software v5.2 (Thermo Fisher Scientific). Coverage maps were generated using the coverage analysis plug-in (Thermo Fisher Scientific). In addition, ANNOtate VARiation (ANNOVAR) (34) was used for functional annotation of identified single nucleotide polymorphisms (SNPs) to investigate their genomic locations and variations (35). To eliminate error artifacts, sequence data were visually confirmed using the Integrative Genomics Viewer (Broad Institute, Cambridge, MA, USA). This workflow was able to report SNPs and indels in as low as $1 \%$ of the variant allele fraction. Based on the results of a feasibility study, the variant allele fraction threshold was set to 5\%. Copy number analysis was performed using the copy number module within the aforementioned workflow of the Ion Reporter Software v5.2 (Thermo Fisher Scientific). Copy numbers of 4 or greater were considered concordant if the same copy number was reported for target genes by the orthogonal assay. Fusions were detected using the fusion detection module in the Ion Reporter Software (Thermo Fisher Scientific) workflow. This pipeline only reported fusions that were previously annotated, as defined in a reference file preloaded into the workflow $(30,31)$.

\section{Results}

Clinical characteristics (Table I). Figure 1 summarizes the clinicopathological, immunophenotypical, and molecular characteristics of eight ISMCs. The patients were between 31 and 54 years old (mean $=42.3$ years), and had no previous gynecological history. Five and two patients presented with vaginal bleeding and discharge, respectively. Seven patients whose MRI scans were available had visible masses in the uterine cervix. Three tumors appeared to involve the vagina, whereas four tumors were confined within the cervix without any evidence of parametrial or vaginal extension. Two patients (cases 3 and 5) received preoperative neoadjuvant concurrent chemoradiation therapy (CCRT). All patients underwent radical $(7 / 8)$ or total $(1 / 8)$ hysterectomy with bilateral salpingo-oophorectomy (4/8), unilateral salpingooophorectomy (1/8), bilateral salpingectomy (4/8), pelvic lymph node dissection (6/8), pelvic lymph node sampling $(1 / 8)$, and para-aortic lymph node dissection (1/8). Three (cases 5, 7, and 8) patients had stage IIIC1 tumors with pelvic lymph node metastases. The remaining five cases were diagnosed as stage IIA2 (1/8), IB2 (3/8), and IA1 (1/8) tumors. Two cases (cases 1 and 5) showed extension into both the adnexa and vagina. One patient with stage IIA2 tumor (case 1) received postoperative radiation therapy (RT). Two patients with stage IB2 (case 2) and IA1 (case 4) tumors and two patients who underwent preoperative CCRT (cases 3 and 5) did not receive further treatment. Three patients with stage IB2 (case 6) and IIIC1 (cases 7 and 8) underwent postoperative CCRT.

Five patients (cases 1, 2, 3, 5, and 7) developed local or metastatic recurrence in the vaginal stump, adnexa, pelvic sidewall, inguinal lymph nodes, small bowel, or lungs. Disease-free survival (DFS) ranged from 7 to 19 months (mean=12.1 months). The patients underwent chemotherapy (4/5) or CCRT (1/5) for recurrent tumors. All patients are currently alive with a mean postoperative follow-up of 21.5 months (range=12-35 months).

Pathological characteristics (Table II). Gross observations revealed the ISMCs as relatively well-demarcated, round, nodular masses. The cut surfaces showed white or gray tan tumors. Tumor necrosis was grossly identifiable in one case. All the patients were infected with high-risk HPV (type 18). The greatest dimension of the tumor ranged from 7 to $65 \mathrm{~mm}$ (mean=36 mm). Five tumors invaded more than half of the cervical stroma, two of which extended through the full thickness of the cervical stroma into the parametrium. SMILE (3/3) and HSIL (2/3) co-existed with ISMC in three cases. These microscopic non-invasive lesions were identified at the periphery of the main tumor masses. Invasive carcinomas were also noted in two cases, including usual-type endocervical adenocarcinoma (2/2) and squamous cell carcinoma $(1 / 2)$.

The histological features of ISMC were similar to those of SMILE. The tumor cell nests predominantly comprised stratified columnar epithelial cells. Variable-sized, occasionally anastomosing nests and sheets of tumor cells irregularly infiltrated the adjacent stroma and formed fingerlike or broad, bulky projections (Figure 2, upper panel). The nuclei were round to ovoid with pale or vesicular chromatin; conspicuous nucleoli were occasionally observed (Figure 2, upper panel). In all cases, the tumor cells had varying degrees of intracytoplasmic mucin (Figure 2, upper panel). and were positive for mucicarmine, Alcian blue (Figure 2, lower panel), and periodic acid-Schiff staining. A distinct pattern of peripheral nuclear palisading was reported in the majority of cases (Figure 2, lower panel). Desmoplastic stromal reaction and associated inflammatory infiltrates were observed at both the tumor center and the invasive front. Neutrophilic infiltrates were dominant within the tumor cell nests and sheets (Figure 2, lower panel), whereas the stroma 
Table I. Clinical characteristics.

\begin{tabular}{|c|c|c|c|c|c|c|c|c|c|c|c|}
\hline $\begin{array}{l}\text { Case } \\
\text { No }\end{array}$ & $\begin{array}{l}\text { Age } \\
(\mathrm{yr})\end{array}$ & $\begin{array}{l}\text { Presenting } \\
\text { symptom }\end{array}$ & $\begin{array}{l}\text { Imaging } \\
\text { findings }\end{array}$ & $\begin{array}{l}\text { Surgical } \\
\text { treatment }\end{array}$ & $\begin{array}{l}\text { FIGO } \\
\text { stage }\end{array}$ & $\begin{array}{c}\text { Postoperative } \\
\text { treatment }\end{array}$ & $\begin{array}{c}\text { Postoperative } \\
\text { recurrence }\end{array}$ & $\begin{array}{l}\text { Treatment for } \\
\text { recurrence }\end{array}$ & $\begin{array}{l}\text { DFS } \\
(\mathrm{mo})\end{array}$ & $\begin{array}{c}\text { Current } \\
\text { status }\end{array}$ & $\begin{array}{c}\text { OS } \\
(\mathrm{mo})\end{array}$ \\
\hline 1 & 35 & $\begin{array}{c}\text { Vaginal } \\
\text { bleeding }\end{array}$ & $\begin{array}{l}\text { A cervical tumor } \\
\text { with upper } \\
\text { vaginal extension; } \\
\text { no PM extension; } \\
\text { borderline-sized } \\
\text { iliac chain LN; } \\
\text { no peritoneal seeding }\end{array}$ & $\begin{array}{l}\text { RH with BS } \\
\text { and PLND }\end{array}$ & IIA2 & RT & $\begin{array}{c}\text { Present } \\
\text { (adnexa and lungs) }\end{array}$ & CT & 12 & Alive & 23 \\
\hline 2 & 54 & $\begin{array}{c}\text { Vaginal } \\
\text { bleeding }\end{array}$ & $\begin{array}{l}\text { A cervical tumor } \\
\text { without vaginal } \\
\text { extension; no PM } \\
\text { extension; no LN } \\
\text { metastasis; no } \\
\text { peritoneal seeding }\end{array}$ & $\begin{array}{c}\text { RH with } \\
\text { BSO and } \\
\text { PLND }\end{array}$ & IB2 & None & $\begin{array}{c}\text { Present } \\
\text { (vaginal stump) }\end{array}$ & CCRT & 9 & Alive & 19 \\
\hline 3 & 45 & $\begin{array}{l}\text { Vaginal } \\
\text { discharge }\end{array}$ & $\begin{array}{l}\text { (Before CCRT) } \\
\text { A cervical tumor } \\
\text { (28 mm) with upper } \\
\text { vaginal extension; } \\
\text { no LN extension; } \\
\text { no LN metastasis; } \\
\text { no peritoneal seeding; } \\
\text { (1 mo after CCRT) } \\
\text { Decrease in tumor } \\
\text { size }(17 \mathrm{~mm}) \text {; } \\
(3 \mathrm{mo} \text { after } \\
\text { CCRT) Decrease } \\
\text { in tumor size }(9 \mathrm{~mm}) \text {; } \\
(11 \mathrm{mo} \text { after } \\
\text { CCRT) Increase } \\
\text { in tumor size } \\
(15 \mathrm{~mm})\end{array}$ & $\begin{array}{l}\text { RH with } \\
\text { BSO after } \\
\text { preoperative } \\
\text { CCRT }\end{array}$ & IB2 & None & $\begin{array}{c}\text { Present } \\
\text { (vaginal stump, } \\
\text { inguinal LN, } \\
\text { and small bowel) }\end{array}$ & CT & 7 & Alive & 28 \\
\hline 4 & 39 & $\begin{array}{l}\text { Abnormal } \\
\text { cytology }\end{array}$ & None & $\begin{array}{l}\text { RH with BS } \\
\text { and PLNS }\end{array}$ & IA1 & None & Absent & None & 19 & Alive & 19 \\
\hline 5 & 39 & $\begin{array}{c}\text { Vaginal } \\
\text { bleeding }\end{array}$ & $\begin{array}{c}\text { (Before CCRT) } \\
\text { A cervical tumor } \\
(55 \mathrm{~mm}) \text { without } \\
\text { vaginal extension; } \\
\text { no PM extension; } \\
\text { no LN metastasis; } \\
\text { no peritoneal seeding; } \\
\text { ( } 2 \text { mo after CCRT) } \\
\text { Decrease in tumor } \\
\text { size ( } 29 \mathrm{~mm}) ; \\
\text { (4 mo after CCRT) } \\
\text { Increase in tumor } \\
\text { size (34 mm) with } \\
\text { endocervical and } \\
\text { PM extension }\end{array}$ & $\begin{array}{l}\text { RH with BSO } \\
\text { and PLND } \\
\text { after } \\
\text { preoperative } \\
\text { CCRT }\end{array}$ & IIIC1 & None & $\begin{array}{c}\text { Present } \\
\text { (pelvic sidewall) }\end{array}$ & CT & 7 & Alive & 20 \\
\hline 6 & 44 & $\begin{array}{c}\text { Vaginal } \\
\text { bleeding }\end{array}$ & $\begin{array}{l}\text { A cervical tumor } \\
\text { without vaginal } \\
\text { extension; no PM } \\
\text { extension; } \\
\text { borderline-sized } \\
\text { right obturator LN; } \\
\text { no peritoneal seeding }\end{array}$ & $\begin{array}{l}\text { RH with BS } \\
\text { and PLND }\end{array}$ & IB2 & CCRT & Absent & None & 16 & Alive & 16 \\
\hline
\end{tabular}


Table I. Continued

\begin{tabular}{|c|c|c|c|c|c|c|c|c|c|c|c|}
\hline $\begin{array}{l}\text { Case } \\
\text { No }\end{array}$ & $\begin{array}{l}\text { Age } \\
(\mathrm{yr})\end{array}$ & $\begin{array}{l}\text { Presenting } \\
\text { symptom }\end{array}$ & $\begin{array}{l}\text { Imaging } \\
\text { findings }\end{array}$ & $\begin{array}{l}\text { Surgical } \\
\text { treatment }\end{array}$ & $\begin{array}{l}\text { FIGO } \\
\text { stage }\end{array}$ & $\begin{array}{c}\text { Postoperative } \\
\text { treatment }\end{array}$ & $\begin{array}{l}\text { Postoperative } \\
\text { recurrence }\end{array}$ & $\begin{array}{l}\text { Treatment for } \\
\text { recurrence }\end{array}$ & $\begin{array}{l}\text { DFS } \\
(\mathrm{mo})\end{array}$ & $\begin{array}{c}\text { Current } \\
\text { status }\end{array}$ & $\begin{array}{l}\text { OS } \\
(\mathrm{mo})\end{array}$ \\
\hline 7 & 51 & $\begin{array}{l}\text { Vaginal } \\
\text { bleeding }\end{array}$ & $\begin{array}{l}\text { A cervical tumor } \\
\text { with mid-vaginal } \\
\text { extension and PM } \\
\text { extension; right } \\
\text { obturator LN } \\
\text { metastasis; no } \\
\text { peritoneal seeding }\end{array}$ & $\begin{array}{c}\text { TH with BSO, } \\
\text { PLND, and } \\
\text { PALND }\end{array}$ & IIIC1 & CCRT & Present (lung) & $\mathrm{CT}$ & 15 & Alive & 35 \\
\hline 8 & 31 & $\begin{array}{c}\text { Vaginal } \\
\text { discharge }\end{array}$ & $\begin{array}{l}\text { A cervical tumor } \\
\text { without vaginal } \\
\text { extension; no PM } \\
\text { extension; iliac } \\
\text { chain LN metastasis; } \\
\text { no peritoneal seeding }\end{array}$ & $\begin{array}{l}\text { RH with LSO, } \\
\text { RS, and PLND }\end{array}$ & IIIC1 & CCRT & Absent & None & 12 & Alive & 12 \\
\hline
\end{tabular}

BS: Bilateral salpingectomy; BSO: bilateral salpingo-oophorectomy; CCRT: concurrent chemoradiation therapy; CT: chemotherapy; DFS: diseasefree survival; FIGO: International Federation of Gynecology and Obstetrics; LN: lymph node,; LSO: left salpingo-oophorectomy; mo: months,; OS: overall survival; PALND: paraaortic lymph node dissection; PLND: pelvic lymph node dissection; PLNS: pelvic lymph node sampling; PM: parametrium; RH: radical hysterectomy; RS: right salpingectomy; RT: radiation therapy; TH: total hysterectomy; yr: year.

displayed extensive lymphoplasmacytic infiltrates. Occasionally, dilated cystic spaces filled with eosinophilic secretions, neutrophils, and nuclear debris were identified. In all cases, numerous apoptotic bodies and mitotic figures were detected throughout the tumor (Figure 2, lower panel). Atypical mitoses were often observed.

Three tumors (cases 1, 3, and 5) had unusual and interesting clinicopathological features. In case 1, FIGO stage IIA2 ISMC had substantial LVSI, but the pelvic lymph nodes were free of tumor. Notably, scattered microscopic foci showing poorly differentiated carcinomas were observed between the areas of typical ISMC (Figure 3, upper panel). Variable-sized solid sheets of tumor cells possessed markedly pleomorphic nuclei with apparent irregularities of the nuclear membrane and prominent red nucleoli. Large areas of coagulative tumor cell necrosis and occasional multinucleated giant cells exhibiting nuclei similar to those of tumor cells were identified. In some foci, tumor cells were showing irregular-shaped, ill-formed cords and trabecular arrangement (Figure 3, upper panel). The intervening stroma was small or absent, and atypical mitoses were frequently detected (Figure 3, upper panel). We also found unusual histological features in two patients (cases 3 and 5) who received preoperative CCRT. In case 3, the patient was diagnosed with adenosquamous carcinoma in the conization specimen. Three months after CCRT, the cervical tumor size significantly decreased from 28 to 9 $\mathrm{mm}$, but an enlarged tumor $(15 \mathrm{~mm})$ was observed in the follow-up MRI obtained 11 months after CCRT. The radical hysterectomy specimen revealed a typical morphology of
ISMC, consisting of nests and cords of stratified mucincontaining columnar cells showing irregular-shaped, fingerlike stromal infiltration and associated desmoplastic reaction. However, the degree of stromal inflammatory infiltration was lower and the number of intraepithelial neutrophils was smaller as compared to those in a typical ISMC. Chemotherapy-induced tumor necrosis was observed in multifocal area (Figure 3, lower panel). Peripheral nuclear palisading was not detected. The degree of stromal inflammatory infiltration was lesser, and the number of intraepithelial neutrophils were smaller. Instead, the tumor cells showed vesicular chromatin, prominent cherry-red nucleoli, markedly irregular nuclear membranes, abundant cytoplasm with low nuclear-to-cytoplasmic ratio, and distinct cell borders (Figure 3, lower panel). These morphological features are compatible with CCRT-induced cytological alterations. In another patient who received preoperative CCRT (case 5), the tumor size decreased at 2 months after CCRT but eventually progressed with endocervical and parametrial extension at 4 months. In addition to CCRT-induced epithelial atypia, we also noted compactly aggregated, large, round tumor cells possessing abundant intracytoplasmic mucin displacing the nucleus to one side of the cell (Figure 3, lower panel). The nuclei were atypical and crescent-shaped, with prominent nucleoli and frequent mitotic figures. These histological features resembled those of the signet-ring cell-type mucinous carcinoma. There was no extracellular mucin pool around the tumor cells. Intraepithelial inflammatory infiltrates were prominent, most of which were neutrophils. 


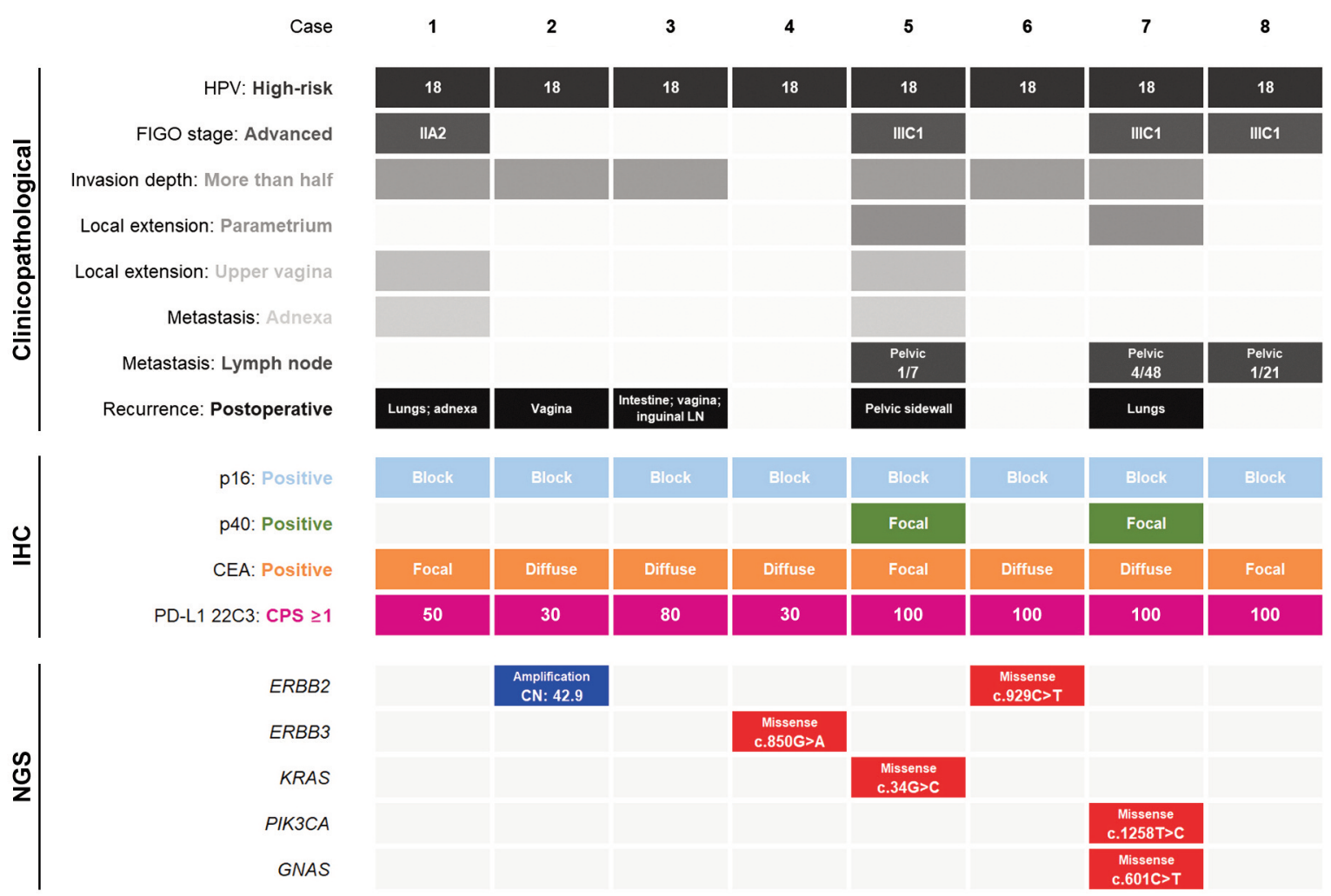

Figure 1. Summary of clinicopathological and molecular characteristics of invasive stratified mucin-producing carcinoma.

Immunostaining results (Table III). All ISMCs and SMILEs displayed diffused and strong p16 immunoreactivity in both the nucleus and cytoplasm (block p16 positivity; Figure 4, upper panel). Areas of squamous cell carcinoma and usualtype endocervical adenocarcinomas also showed block positivity for $\mathrm{p} 16$. Two tumors had a small number of $\mathrm{p} 40$ positive cells that had moderate to strong staining intensity (Figure 4, upper panel). In the remaining cases, some blandappearing squamous epithelium located at the periphery of tumor cell nests was positive for p40. HSIL was uniformly and intensely positive for both p16 and p40. All ISMCs and SMILEs showed strong cytoplasmic CEA expression with a variable proportion of staining. Five ISMCs were diffusely positive for CEA, whereas three were patchy (Figure 4, upper panel). One tumor showed uniform and strong c-erbB2 immunoreactivity in the membrane of the tumor cells (Figure 4, upper panel). PD-L1 22C3 immunostaining revealed high CPS in all cases, ranging from 30 to 100 (mean=73.8). PDL1 was localized within both the tumor cells and tumorassociated immune cells present in the peritumoral stroma (Figure 4, middle and lower panels).

Targeted sequencing results. Targeted sequencing revealed six pathogenic mutations in five patients. Table III summarizes the single nucleotide variations and copy number alterations identified in the five patients with ISMC. Four tumors harbored pathogenic missense mutations in erbb2 receptor tyrosine kinase 3 (ERBB3; c.850G $>\mathrm{A}$; p.Gly284Arg; case 4), v-Ki-ras2 Kirsten rat sarcoma viral oncogene homolog (KRAS; c.34G>C; p.Gly12Arg; case 5), erb-b2 receptor tyrosine kinase 2 (ERBB2; c.929C $>\mathrm{T}$, p.Ser310Phe; case 6), phosphatidylinositol-4,5-bisphosphate 3-kinase catalytic subunit alpha ( $P I K 3 C A$; c.1258T $>\mathrm{C}$; p.Cys420Arg; case 7), guanine nucleotide binding protein, alpha stimulating (GNAS; c.601C>T; p.Arg201Cys; case 7). One tumor harbored $E R B B 2$ amplification (copy number: 42.9; case 2). Diffused and strong membranous c-erbB2 expression was concordant with amplification.

\section{Discussion}

Here, we describe the morphological and immunophenotypical characteristics of cervical ISMC and delineate the overall genetic alterations. The most common presenting symptom of ISMC is vaginal bleeding (6). Some patients only showed abnormal cytology findings without symptoms. In a recent largest cohort study of 52 ISMC patients by Stolnicu et al. (7), the mean age of patients was 41.8 years (range $=22-78$ years). 
Table II. Pathological characteristics.

\begin{tabular}{|c|c|c|c|c|c|c|c|c|c|c|}
\hline $\begin{array}{l}\text { Case } \\
\text { No }\end{array}$ & $\begin{array}{l}\text { HPV status } \\
\text { (type) }\end{array}$ & $\begin{array}{l}\text { Coexisting } \\
\text { pathology }\end{array}$ & $\begin{array}{c}\text { Greatest } \\
\text { dimension } \\
(\mathrm{mm})\end{array}$ & $\begin{array}{l}\text { Invasion depth/ } \\
\text { entire stromal } \\
\text { thickness }(\mathrm{mm})\end{array}$ & $\begin{array}{c}\text { Parametrial } \\
\text { extension }\end{array}$ & LVSI & $\begin{array}{l}\text { Vaginal } \\
\text { extension }\end{array}$ & $\begin{array}{l}\text { Adnexal } \\
\text { extension }\end{array}$ & $\begin{array}{l}\text { Lymph node } \\
\text { metastasis }\end{array}$ & $\begin{array}{l}\text { Peritoneal } \\
\text { metastasis }\end{array}$ \\
\hline 1 & HR (18) & None & 55 & $20 / 22$ & - & + & + & + & - & - \\
\hline 2 & HR (18) & None & 20 & $6 / 9$ & - & - & - & - & - & - \\
\hline 3 & HR (18) & None & 20 & $18 / 22$ & - & - & - & - & - & - \\
\hline 4 & HR (18) & SMILE, HSIL, and UEA & 7 & $2 / 11$ & - & - & - & - & - & - \\
\hline 5 & HR (18) & None & 33 & $20 / 20$ & + & + & + & + & $+(1 / 7 ;$ pelvic $)$ & - \\
\hline 6 & HR (18) & SMILE and HSIL & 30 & $11 / 24$ & - & - & - & - & - & - \\
\hline 7 & HR (18) & SCC and UEA & 65 & $16 / 16$ & + & + & - & - & $+(4 / 48 ;$ pelvic $)$ & - \\
\hline 8 & HR (18) & SMILE & 55 & $5 / 12$ & _- & - & _- & _- & $+(1 / 21 ;$ pelvic $)$ & _- \\
\hline
\end{tabular}

HPV: Human papillomavirus; HR: high-risk; HSIL: high-grade squamous intraepithelial lesion; LVSI: lymphovascular space invasion; SCC: squamous cell carcinoma; SMILE: stratified mucin-producing intraepithelial lesion; UEA: usual-type endocervical adenocarcinoma.

Eighty percent of the patients developed ISMC before 50 years of age. FIGO stage I was the most common $(70 \%)$, followed by stage III (11.5\%), II (9.6\%), and IV (1.9\%). The presence of the ISMC component is a determinant of a poor outcome. The rates of lymph node metastasis and local recurrence were higher in ISMC (33\% and 25\%, respectively) than in the usual-type endocervical adenocarcinoma $(12.2 \%$ and $8.8 \%$, respectively) (7). Moreover, no significant differences were observed in overall survival and recurrencefree survival between patients with pure ISMC and those with mixed ISMC and other HPV-associated endocervical adenocarcinomas ( $p=0.287$ and $p=0.185$, respectively) (7). In this study, the mean age of patients was 42.3 years, consistent with that reported by Stolnicu et al. (7) (41.8 years) and Horn et al. (6) (47.1 years). Lymph node metastases were found in three patients $(37.5 \%)$, and distant metastases were detected in the lungs, adnexae, inguinal lymph nodes, and small intestines of three patients $(37.5 \%)$. Three patients $(37.5 \%)$ experienced postoperative local recurrence at the vaginal stump and pelvic sidewall. These findings are consistent with previous data demonstrating ISMC as an aggressive subtype of endocervical adenocarcinoma, frequently associated with nodal and distant metastases as well as recurrences (5-7).

In this study, two patients underwent neoadjuvant CCRT before surgery. The preoperative FIGO stages were IIA1 and IB3. In one patient with IIA1 tumor (case 3), the tumor size decreased after two cycles of CCRT but increased later after the third cycle. In the other patient with stage IB3 tumor (case 5), the tumor size decreased 2 months after CCRT (55 to $29 \mathrm{~mm}$ ). However, parametrial extension, vaginal extension, peritoneal metastasis, and pelvic lymph node metastases developed 4 months after CCRT, resulting in upstaging of the final pathology (IIIC1). The DFS was 7 months in both patients. There have been no data on the outcomes of patient subjected to preoperative CCRT with subsequent surgery for ISMC. Our observations suggest that patients with ISMC appear to respond well to the first or second cycles of CCRT but eventually show disease progression with local recurrence or distant metastasis.

ISMC is an invasive counterpart of SMILE. They share characteristic histological features (5), including stratified immature epithelial cells, abundant intracytoplasmic mucinous vacuoles in the entire epithelial thickness, numerous intraglandular neutrophils and apoptotic debris, and peripheral nuclear palisading. In ISMC, variable-sized sheets or nests of tumor cells infiltrate the stroma in a fingerlike growth pattern and are accompanied by a desmoplastic stromal reaction. In contrast, intercellular bridges and keratin pearl formation were not observed, and glandular formation was rarely identified. Adenosquamous carcinoma is one of the main differential diagnoses of ISMC that displays histological evidence of both adenocarcinoma and squamous cell carcinoma (2). In ISMC, individual cell keratinization, intercellular bridges, and gland formation were not identified. The lack of squamous and glandular differentiation makes it possible to distinguish between ISMC and adenosquamous carcinoma. In this study, two patients were misdiagnosed with adenosquamous carcinoma on conization and total hysterectomy specimens. One patient (case 3) who received three cycles of CCRT after conization experienced disease progression. The current guidelines for cervical carcinoma recommend the same CCRT protocol regardless of the histological subtype (36). However, pathologists should properly distinguish ISMC from adenosquamous carcinoma, as these two entities may differ in clinicopathological characteristics and response to CCRT.

Another main differential diagnosis is HPV-associated mucinous carcinoma of the signet-ring cell type. Primary signet-ring cell carcinoma of the uterine cervix is exceedingly rare, and only a few cases have been reported 

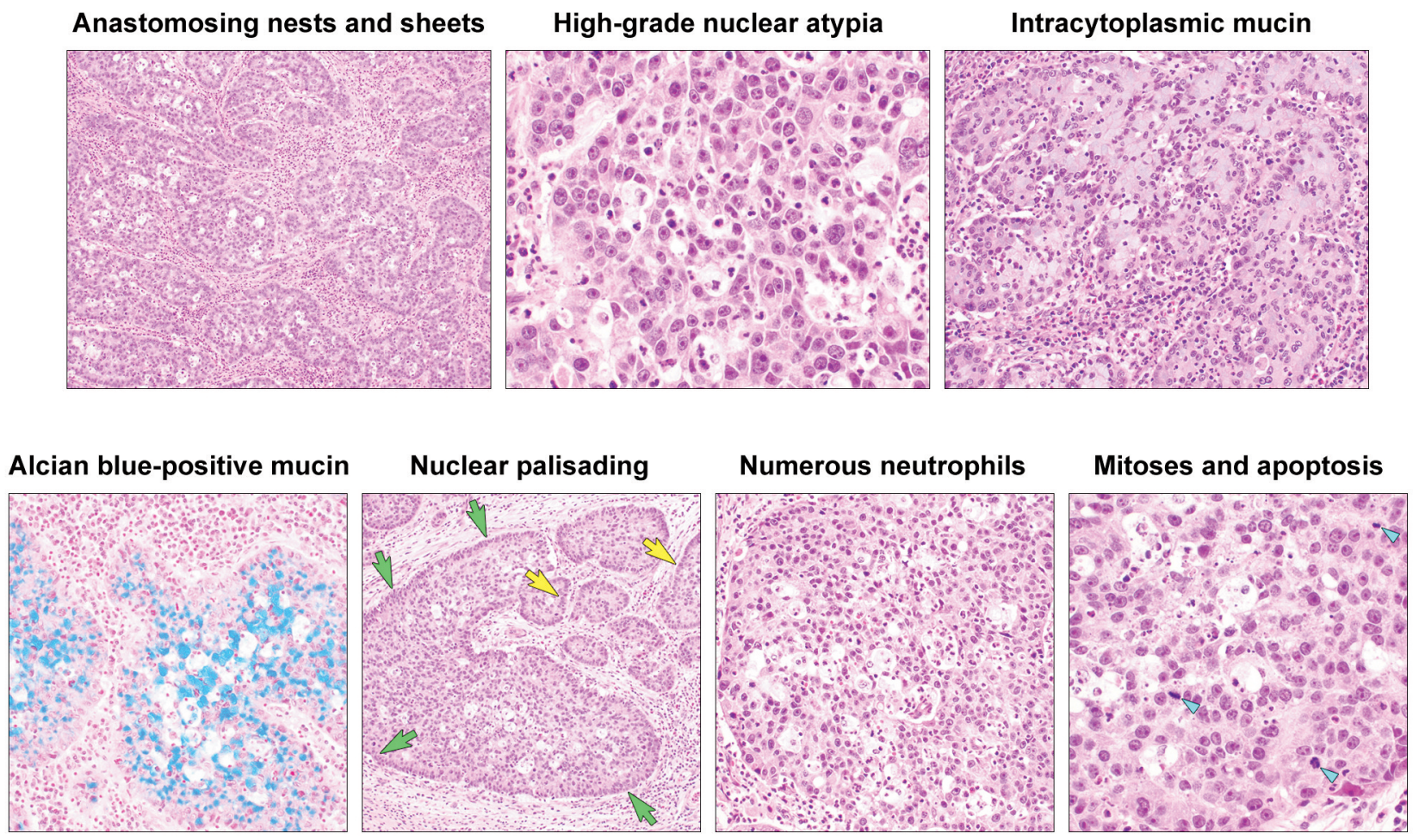

Figure 2. Typical histological findings of invasive stratified mucin-producing carcinoma. (Upper panels) Variable-sized, irregular-shaped, and interanastomosing nests and sheets of stratified columnar epithelial cells display high-grade nuclear atypia, including severe pleomorphism, vesicular chromatin, and prominent eosinophilic nucleoli. (Lower panels) Abundant intracytoplasmic mucin is highlighted by Alcian blue. Large (green arrows) and small (yellow arrows) cellular sheets show characteristic nuclear palisading at the periphery. They also possess numerous intraepithelial and stromal neutrophils. The tumor cells show readily identifiable apoptotic bodies and mitotic figures (small blue arrowheads).

to date (37). Histologically, the tumor displays characteristic infiltration by mucin-containing tumor cells arranged in clusters as well as singly scattered, and possessing hyperchromatic, crescent-shaped, eccentrically located nuclei. In this study, one tumor (case 5) had a signet-ring cell morphology. The tumor cells were filled with mucin vacuoles that pushed the nucleus to the periphery of the cytoplasm. The amount of intracytoplasmic mucin was much higher than that in the adjacent ISMC cells. Most of the cells were arranged in nests and clusters, and singly dispersed cells were rare. These morphological features were consistent with the mucinous carcinoma of the signet-ring cell type. We observed that this patient with ISMC showing areas of signet-ring cell morphology developed disease progression despite CCRT. Given its rarity, the clinical outcome of patients with ISMC coexisting with signet-ring cell carcinoma has not yet been reported. We cannot exclude the possibility that ISMC cells underwent CCRT-induced cytological alterations, including an increase in the amount of intracytoplasmic mucin, resulting in signet-ring cell-like features. Further investigations using more ISMC cases with similar histological features are warranted to clarify the pathogenesis and clinical significance of signet-ring cell carcinoma associated with ISMC.

As both SMILE and ISMC are associated with high-risk HPV infection, they demonstrate block positivity for $\mathrm{p} 16$ protein (3). In this study, all SMILEs and ISMCs displayed block p16 positivity, and all patients were infected with HPV type 18. These results are in concordance with previous data showing that the most prevalent HPV type in ISMC patients is type 18 (7). SMILE and ISMC shared the same p63 immunostaining pattern, and showed negative or weakly focal positive staining (3). In a recent study by Stolnicu et al. (38) investigating the immunophenotype of ISMC using tissue microarray, the positive rates of p63, p40, and GATA3, markers related to squamous differentiation, were $25.0 \%, 28.6 \%$, and $14.3 \%$, respectively. In particular, p63 and p40 proteins were localized in the periphery of the tumor cell nests. In this study, two tumors (25\%) showed focal and strong nuclear p40 immunoreactivity. The p40-positive tumor cells were located along the border of the tumor cell nests. 
Poorly differentiated area

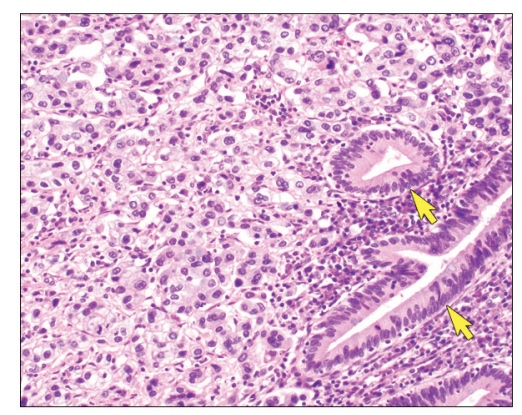

Poorly formed cords and trabeculae

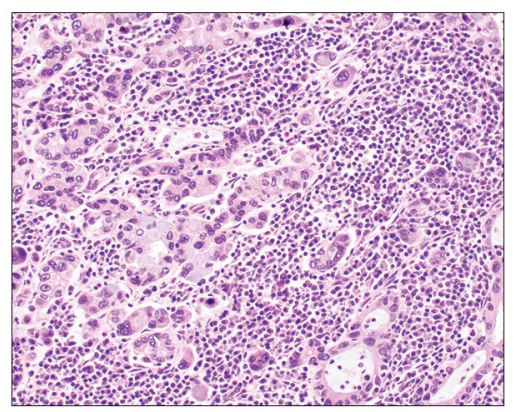

Little or no intervening stroma

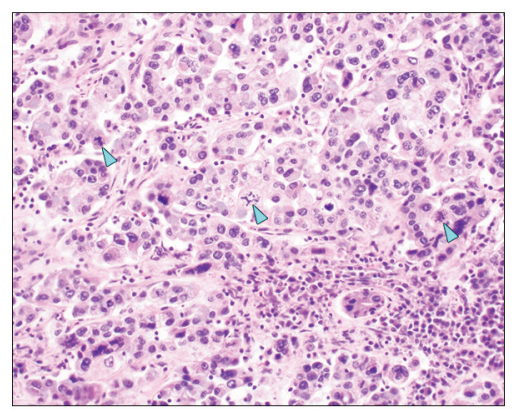

Chemotherapy-induced necrosis

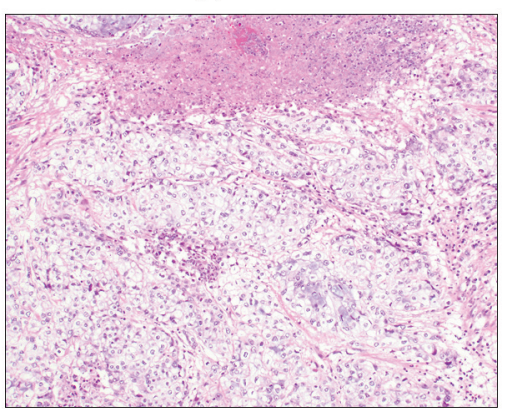

Marked nuclear pleomorphism

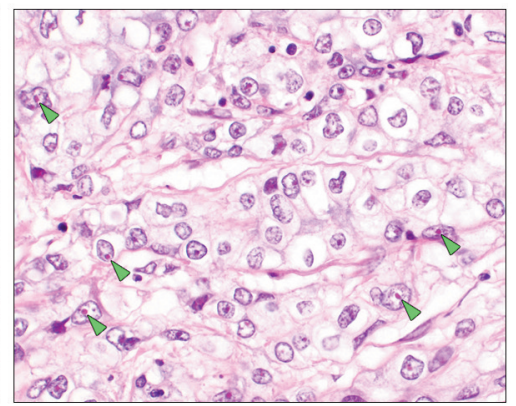

Signet-ring cells

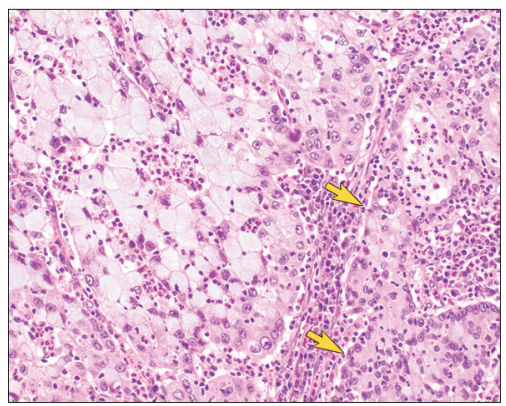

Figure 3. Unusual histological findings of invasive stratified mucin-producing carcinoma. (Upper panels) Areas of poorly differentiated carcinoma are located closely adjacent to those of usual-type endocervical adenocarcinoma (yellow arrows). Poorly formed cords and trabeculae and randomly distributed individual tumor cells are occasionally noted. In areas lacking the intervening stroma, frequent atypical mitoses (small blue arrowheads) are often identified. (Lower panels) Neoadjuvant chemotherapy leads to tumor cell necrosis and cytological alterations including abundant, clear cytoplasm, severe irregularities of nuclear membrane, and marked nuclear pleomorphism, and cherry-red nucleoli (small green arrowheads). Tight aggregates of signet-ring cells possess abundant intracytoplasmic mucin, displacing the nucleus to one side of the cell. They are located closely adjacent to a typical area of ISMC (orange arrows).

Heeren et al. (39) reported that both tumor cells and various immune cells expressed PD-L1 in squamous cell carcinoma and adenocarcinoma of the uterine cervix. In comparison with endocervical adenocarcinoma, squamous cell carcinoma was more frequently positive for PD-L1 and showed more PD-L1positive immune cells. The authors also documented that DFS was significantly shorter in patients with endocervical adenocarcinoma who had PD-L1-expressing tumor-associated macrophages than in those with PD-L1-negative tumors (39). In a recent study by Karpathiou et al. (40) using 27 endocervical adenocarcinoma samples, one $(3.7 \%)$ showed positive PD-L1 expression in the tumor cells, while two (7.4\%) exhibited PD-L1 positivity in the immune cells. Despite these low frequencies, PD-L1 expression by either tumor cells or immune cells was significantly associated with worse prognosis in patients with endocervical adenocarcinoma (40). In this study, we evaluated PD-L1 expression in patients with ISMC using the CPS system for the first time. All cases showed PD-L1 over-expression with CPS ranging from 30 to
100. This finding raises the possibility that PD-L1 overexpression may contribute to the aggressive behavior and worse prognosis of ISMC. Given that pembrolizumab, an antiPD-1 inhibitor, is indicated for the treatment of patients with advanced cervical carcinoma with PD-L1-positive tumors (CPS $\geq 1$ ), as determined by an FDA-approved test, and provides a better outcome among patients with recurrent or metastatic cervical carcinoma (41), patients with ISMC can be promising candidates who can benefit from PD-1/PD-L1 immunotherapy.

Targeted sequencing results indicated that ISMCs are genetically heterogeneous. Our cases harbored pathogenic mutations in PIK3CA, KRAS, ERBB2, and ERBB3, which are commonly observed in endocervical adenocarcinoma or squamous cell carcinoma (42-44). These findings suggest that ISMC does not harbor characteristic or specific somatic mutations but has molecular profiles similar to those of other cervical carcinomas. Interestingly, ERBB2 amplification (copy number: 42.9) was observed in one case. Shi et al. (45) 


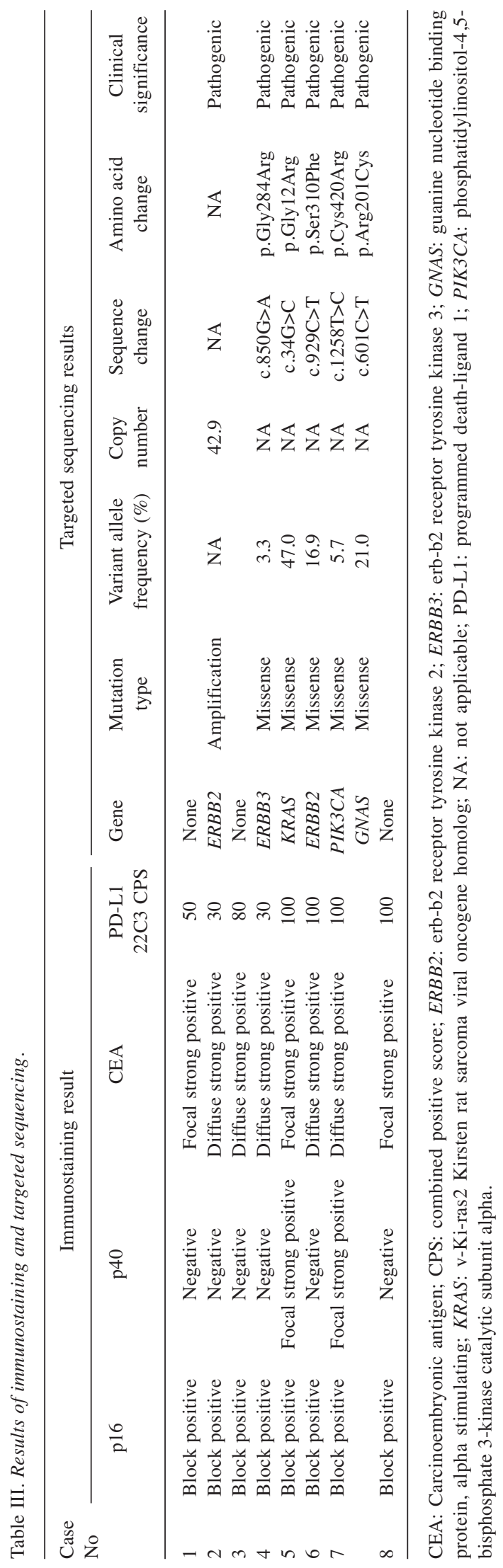

demonstrated that ERBB2 amplification was detected in $6.2 \%$ of all endocervical adenocarcinoma cases. Their study included 10 ISMC cases, but there was no ERBB2-amplified ISMC. Stolnicu et al. (38) reported that c-erbB2 over-expression was rare in endocervical adenocarcinoma, and that only $12.5 \%$ of ISMCs were positive for c-erbB2 on immunostaining. Our observation that ERBB2 amplification/over-expression was detected in only one of the eight cases suggests that ERBB2 amplification/over-expression rarely occurs in ISMC, consistent with previous reports. Despite its low frequency, ERBB2 can be a potential therapeutic target for ISMC and may provide physicians with options other than conventional chemotherapy.

The association of PIK3CA mutation with worse prognosis or chemotherapeutic resistance in patients with cervical carcinoma remains unclear with conflicting results across studies $(44,46,47)$. In this study, a (plain) PIK3CA mutation was detected in one patient. The patient had lymph node metastasis at the time of surgery and developed lung metastasis 15 months after surgery. The prognostic impact of PIK3CA mutation is inconclusive in only a single case. Furthermore, the PIK3CA p.Cys420Arg mutation is a rarely identified variant as compared to p.Glu545Lys and p.Glu542Lys mutations, thus posing additional difficulties to predict the biological behavior of the tumor. Further molecular studies using a larger cohort of ISMC cases are imperative to analyze the frequency and type of $P I K 3 C A$ mutations in ISMC. As a PIK3CA inhibitor has been demonstrated to be effective in inducing a remarkable regression of cervical carcinoma (48), targeted therapy may also be applicable in patients with PIK3CA-mutant ISMC.

$K R A S$ mutation has been shown to be an independent predictor of disease recurrence in patients with cervical carcinoma and exhibits significant association with shorter DFS (49). In this study, one patient with KRAS-mutant ISMC showed a poor response to preoperative CCRT and the shortest DFS of 7 months. Similar to PIK3CA mutation, although we cannot draw clinical significance of KRAS mutation with only a single case, recent clinical trials targeting KRAS have achieved encouraging outcomes in patients with advanced non-small cell lung carcinoma, colorectal carcinoma, and other solid tumors (50).

In summary, we analyzed the clinicopathological and molecular characteristics of ISMC of the uterine cervix. Careful morphological examination is critical for accurate diagnosis, as ISMC may be unfamiliar to inexperienced pathologists. Even experienced pathologists may find challenging to distinguish ISMC from other subtypes of endocervical adenocarcinoma. Frequent nodal and distant metastases and poor response to CCRT, as well as postoperative recurrences, indicate the aggressive behavior of ISMC. The molecular profiles of ISMC appear heterogeneous and similar to those of other cervical carcinomas. Most importantly, all tumors displayed PD-L1 

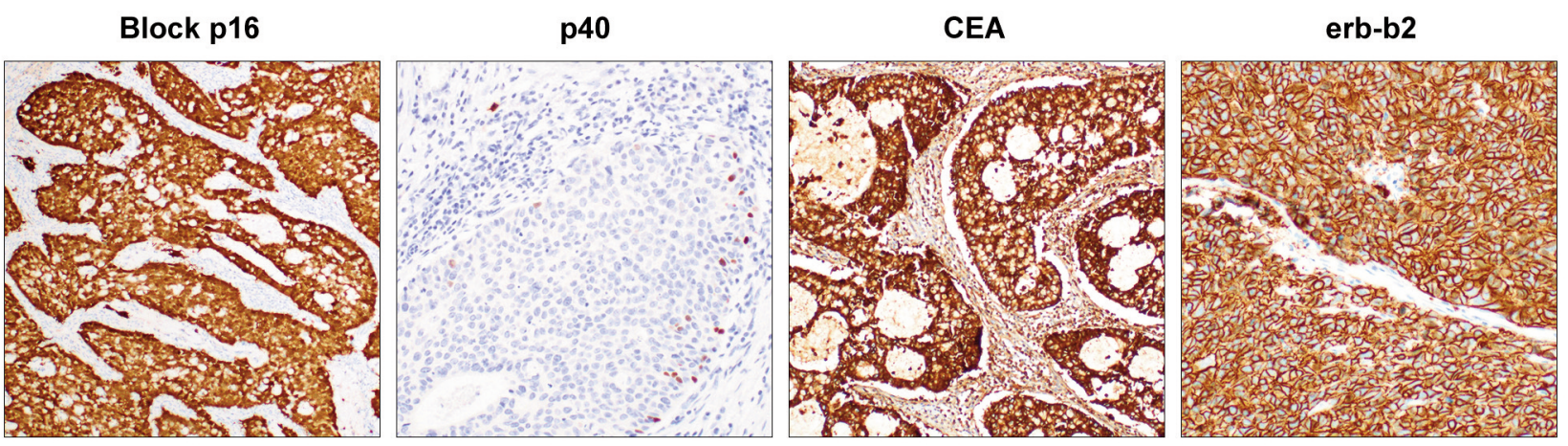

\section{Case 1: PD-L1 CPS 50}
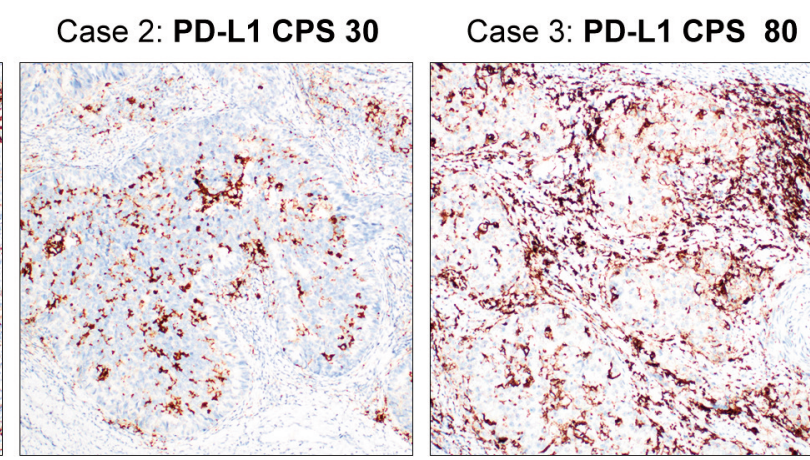

Case 4: PD-L1 CPS 30
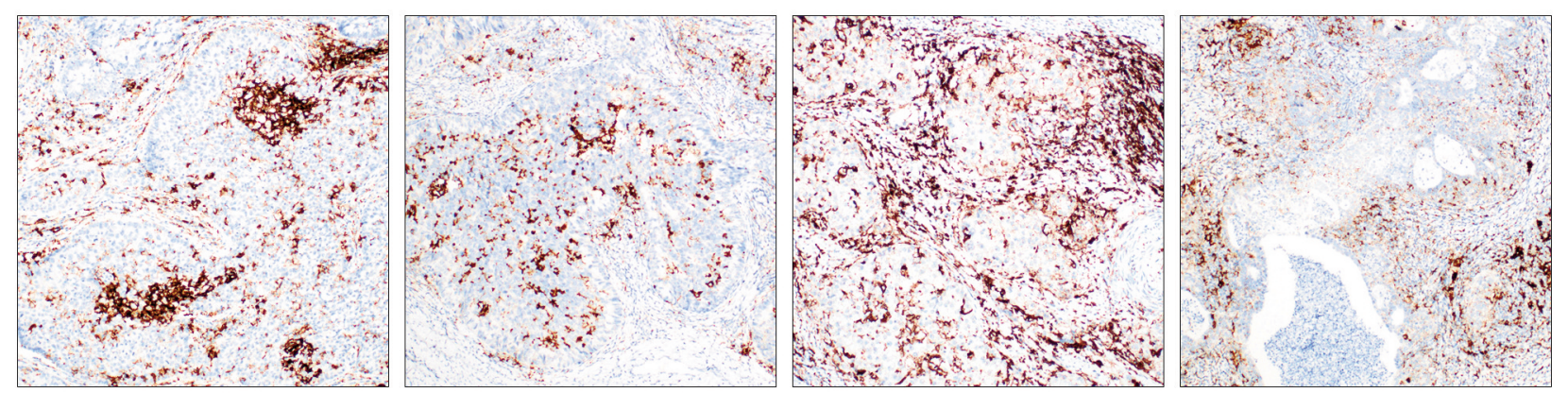

Case 5: PD-L1 CPS 100
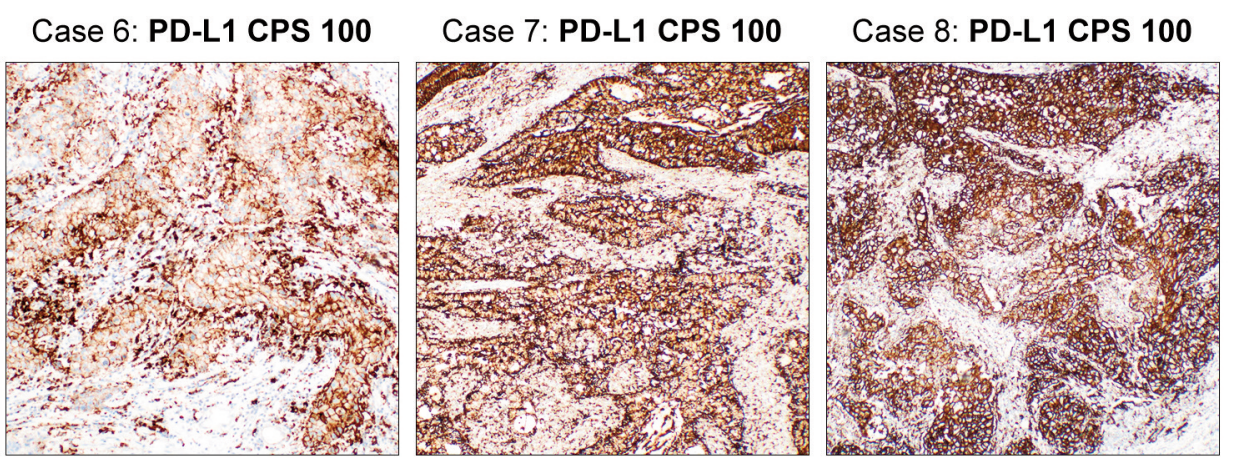

Figure 4. Immunostaining results of invasive stratified mucin-producing carcinoma (ISMC). (Upper panels) ISMC exhibits block p16 positivity, focal nuclear p40 immunoreactivity with moderate intensity, diffuse and intense carcinoembryonic antigen (CEA) expression. Uniform and strong membranous erb-b2 immunoreactivity in almost all tumor cells (score 3+) is identified in one case. (Middle and lower panels) Constant programmed death-ligand $1(P D-L 1)$ over-expression in all cases.

over-expression. Immune checkpoint inhibitors against PDL1/PD-1 may be applicable to patients with ISMC.

\section{Conflicts of Interest}

The Authors declare that they have no conflicts of interest in relation to this study.

\section{Authors' Contributions}

All Authors made substantial contributions to the conception and design of the study, the acquisition, analysis, and interpretation of the data, drafting of the article, critical revision of the article for important intellectual content, and final approval of the version to be published.

\section{References}

1 Park JJ, Sun D, Quade BJ, Flynn C, Sheets EE, Yang A, McKeon $\mathrm{F}$ and Crum CP: Stratified mucin-producing intraepithelial lesions of the cervix: adenosquamous or columnar cell neoplasia? Am J Surg Pathol 24(10): 1414-1419, 2000. PMID: 11023104. DOI: 10.1097/00000478-200010000-00012

2 WHO Classification of Tumors Editorial Board: WHO Classification of Tumours: Female Genital Tumours. IARC, Lyon, 2020 . 
3 Onishi J, Sato Y, Sawaguchi A, Yamashita A, Maekawa K, Sameshima $H$ and Asada Y: Stratified mucin-producing intraepithelial lesion with invasive carcinoma: 12 cases with immunohistochemical and ultrastructural findings. Hum Pathol 55: 174-181, 2016. PMID: 27237368. DOI: 10.1016/j.humpath. 2016.05.007

4 Boyle DP and McCluggage WG: Stratified mucin-producing intraepithelial lesion (SMILE): report of a case series with associated pathological findings. Histopathology 66(5): 658-663, 2015. PMID: 25039487. DOI: 10.1111/his.12498

5 Lastra RR, Park KJ and Schoolmeester JK: Invasive stratified mucin-producing carcinoma and stratified mucin-producing intraepithelial lesion (SMILE): 15 cases presenting a spectrum of cervical neoplasia with description of a distinctive variant of invasive adenocarcinoma. Am J Surg Pathol 40(2): 262-269, 2016. PMID: 26523540. DOI: 10.1097/PAS.0000000000000543

6 Horn LC, Handzel R, Borte G, Siebolts U, Haak A and Brambs $\mathrm{CE}$ : Invasive stratified mucin-producing carcinoma (i-SMILE) of the uterine cervix: report of a case series and review of the literature indicating poor prognostic subtype of cervical adenocarcinoma. J Cancer Res Clin Oncol 145(10): 2573-2582, 2019. PMID: 31385027. DOI: 10.1007/s00432-019-02991-3

7 Stolnicu S, Boros M, Segura S, Horn LC, Parra-Herran C, Oliva E, Abu-Rustum N, Soslow RA and Park KJ: Invasive stratified mucinous carcinoma (iSMC) of the cervix often presents with highrisk features that are determinants of poor outcome: an international multicenter study. Am J Surg Pathol 44(10): 1374-1380, 2020. PMID: 32271191. DOI: 10.1097/PAS.0000000000001485

8 Bhatla N, Aoki D, Sharma DN and Sankaranarayanan R: Cancer of the cervix uteri. Int J Gynaecol Obstet 143 Suppl 2: 22-36, 2018. PMID: 30306584. DOI: 10.1002/ijgo.12611

$9 \mathrm{Na} \mathrm{K}$ and Kim HS: Clinicopathologic and molecular characteristics of mesonephric adenocarcinoma arising from the uterine body. Am J Surg Pathol 43(1): 12-25, 2019. PMID: 29189288. DOI: 10.1097/PAS.0000000000000991

10 Choi S, Na K, Kim SW and Kim HS: Dedifferentiated mesonephric-like adenocarcinoma of the uterine corpus. Anticancer Res 41(5): 2719-2726, 2021. PMID: 33952503. DOI: 10.21873/anticanres.15053

11 Kim HS, DO SI, Kim DH and Apple S: Clinicopathological and prognostic significance of programmed death ligand 1 expression in Korean patients with triple-negative breast carcinoma. Anticancer Res 40(3): 1487-1494, 2020. PMID: 32132048. DOI: 10.21873/anticanres.14093

12 Park S, Cho EY, Oh YL, Park YH and Kim HS: Primary peritoneal high-grade serous carcinoma misinterpreted as metastatic breast carcinoma: a rare encounter in peritoneal fluid cytology. Anticancer Res 40(5): 2933-2939, 2020. PMID: 32366445. DOI: 10.21873/anticanres.14271

13 Jung H, Bae GE, Kim HM and Kim HS: Clinicopathological and molecular differences between gastric-type mucinous carcinoma and usual-type endocervical adenocarcinoma of the uterine cervix. Cancer Genomics Proteomics 17(5): 627-641, 2020. PMID: 32859641. DOI: $10.21873 /$ cgp.20219

14 Choi S, Jung YY and Kim HS: Serous carcinoma of the endometrium with mesonephric-like differentiation initially misdiagnosed as uterine mesonephric-like adenocarcinoma: a case report with emphasis on the immunostaining and the identification of splice site TP53 mutation. Diagnostics (Basel) 11(4): 717, 2021. PMID: 33919505. DOI: 10.3390/diagnostics11040717
15 Park CK, Kim YW, Koh HH, Yoon N, Bae GE and Kim HS: Clinicopathological characteristics of squamous cell carcinoma and high-grade squamous intraepithelial lesions involving endocervical polyps. In Vivo 34(5): 2613-2621, 2020. PMID: 32871791. DOI: 10.21873/invivo.12079

16 Choi S, Cho J, Lee SE, Baek CH, Kim YK, Kim HJ and Ko YH: Adenocarcinoma of the minor salivary gland with concurrent MAML2 and EWSR1 alterations. J Pathol Trans1 Med 55(2): 132138, 2021. PMID: 33472334. DOI: 10.4132/jptm.2020.12.11

17 Choi S, Park S, Chung MP, Kim TS, Cho JH and Han J: A rare case of adenosquamous carcinoma arising in the background of IgG4-related lung disease. J Pathol Transl Med 53(3): 188-191, 2019. PMID: 30853707. DOI: 10.4132/jptm.2019.02.21

18 Jang Y, Jung H, Kim HN, Seo Y, Alsharif E, Nam SJ, Kim SW, Lee JE, Park YH, Cho EY and Cho SY: Clinicopathologic characteristics of HER2-positive pure mucinous carcinoma of the breast. J Pathol Transl Med 54(1): 95-102, 2020. PMID: 31718120. DOI: $10.4132 /$ jptm.2019.10.24

19 Kim H, Kim J, Lee SK, Cho EY and Cho SY: TFE3-expressing perivascular epithelioid cell tumor of the breast. J Pathol Transl Med 53(1): 62-65, 2019. PMID: 30269476. DOI: 10.4132/jptm. 2018.08.30

20 Jung YY, Woo HY and Kim HS: Targeted genomic sequencing reveals novel TP53 in-frame deletion mutations leading to p53 overexpression in high-grade serous tubo-ovarian carcinoma. Anticancer Res 39(6): 2883-2889, 2019. PMID: 31177126. DOI: 10.21873/anticanres.13417

$21 \mathrm{Na} \mathrm{K}$, Lee JY, Sung JY, Kim GM, Koo JS and Kim HS: Comparative clinicopathological and cytomorphological analyses of peritoneal carcinomatosis associated with metastatic breast carcinoma and primary peritoneal/ovarian carcinoma in patients with a history of breast carcinoma. Virchows Arch 473(2): 165-175, 2018. PMID: 29926183. DOI: 10.1007/s00 428-018-2390-5

22 Park CK and Kim HS: Clinicopathological characteristics of ovarian metastasis from colorectal and pancreatobiliary carcinomas mimicking primary ovarian mucinous tumor. Anticancer Res 38(9): 5465-5473, 2018. PMID: 30194204. DOI: 10.21873/anticanres.12879

23 Chung T, DO SI, Na K, Kim G, Jeong YI, Kim YW and Kim HS: Stromal p16 overexpression in gastric-type mucinous carcinoma of the uterine cervix. Anticancer Res 38(6): 3551-3558, 2018. PMID: 29848709. DOI: 10.21873/anticanres.12627

$24 \mathrm{Na} \mathrm{K}$, Sung JY and Kim HS: TP53 mutation status of tuboovarian and peritoneal high-grade serous carcinoma with a wildtype p53 immunostaining pattern. Anticancer Res 37(12): 66976703, 2017. PMID: 29187446. DOI: 10.21873/anticanres.12128

25 Choi S, Joo JW, Do SI and Kim HS: Endometrium-limited metastasis of extragenital malignancies: a challenge in the diagnosis of endometrial curettage specimens. Diagnostics (Basel) 10(3): 150, 2020. PMID: 32164210. DOI: 10.3390/diagnostics 10030150

26 Jang MI, Sung JY, Kim JY and Kim HS: Clinicopathological characteristics of metaplastic papillary tumor of the fallopian tube. Anticancer Res 37(7): 3693-3701, 2017. PMID: 28668862. DOI: 10.21873/anticanres.11741

27 Kim M and Kim HS: Clinicopathological characteristics of welldifferentiated papillary mesothelioma of the peritoneum: a singleinstitutional experience of 12 cases. In Vivo 33(2): 633-642, 2019. PMID: 30804152. DOI: 10.21873/invivo.11521 
28 Rüschoff J, Hanna W, Bilous M, Hofmann M, Osamura RY, Penault-Llorca F, van de Vijver M and Viale G: HER2 testing in gastric cancer: a practical approach. Mod Pathol 25(5): 637-650, 2012. PMID: 22222640. DOI: 10.1038/modpathol.2011.198

29 Huang RSP, Haberberger J, Murugesan K, Danziger N, Hiemenz M, Severson E, Duncan DL, Ramkissoon SH, Ross JS, Elvin JA and Lin DI: Clinicopathologic and genomic characterization of PDL1-positive uterine cervical carcinoma. Mod Pathol 34(7): 14251433, 2021. PMID: 33637877. DOI: 10.1038/s41379-021-00780-3

30 Hovelson DH, McDaniel AS, Cani AK, Johnson B, Rhodes K, Williams PD, Bandla S, Bien G, Choppa P, Hyland F, Gottimukkala R, Liu G, Manivannan M, Schageman J, Ballesteros-Villagrana E, Grasso CS, Quist MJ, Yadati V, Amin A, Siddiqui J, Betz BL, Knudsen KE, Cooney KA, Feng FY, Roh MH, Nelson PS, Liu CJ, Beer DG, Wyngaard P, Chinnaiyan AM, Sadis S, Rhodes DR and Tomlins SA: Development and validation of a scalable next-generation sequencing system for assessing relevant somatic variants in solid tumors. Neoplasia 17(4): 385399, 2015. PMID: 25925381. DOI: 10.1016/j.neo.2015.03.004

31 Jeon J, Maeng LS, Bae YJ, Lee EJ, Yoon YC and Yoon N: Comparing clonality between components of combined hepatocellular carcinoma and cholangiocarcinoma by targeted sequencing. Cancer Genomics Proteomics 15(4): 291-298, 2018. PMID: 29976634. DOI: $10.21873 / \mathrm{cgp} .20087$

32 Yoon N, Kim HS, Lee JW, Lee EJ, Maeng LS and Yoon WS: Targeted genomic sequencing reveals different evolutionary patterns between locally and distally recurrent glioblastomas. Cancer Genomics Proteomics 17(6): 803-812, 2020. PMID: 33099481. DOI: $10.21873 / \operatorname{cgp} .20234$

33 Thermo Fisher Scientific: Oncomine Comprehensive Assays, 2021. Available at: https://www.thermofisher.com $/ \mathrm{kr} / \mathrm{ko} / \mathrm{home} /$ clinical/preclinical-companion-diagnostic-development/oncomineoncology/oncomine-cancer-research-panel-workflow.html [Last accessed on Jul 31, 2021]

34 Wang $\mathrm{K}, \mathrm{Li} \mathrm{M}$ and Hakonarson $\mathrm{H}$ : ANNOVAR: functional annotation of genetic variants from high-throughput sequencing data. Nucleic Acids Res 38(16): e164, 2010. PMID: 20601685 DOI: $10.1093 /$ nar/gkq603

35 Yang $\mathrm{H}$ and Wang K: Genomic variant annotation and prioritization with ANNOVAR and wANNOVAR. Nat Protoc 10(10): 1556-1566, 2015. PMID: 26379229. DOI: 10.1038/nprot.2015.105

36 Yokoi E, Mabuchi S, Takahashi R, Matsumoto Y, Kuroda H, Kozasa $\mathrm{K}$ and Kimura $\mathrm{T}$ : Impact of histological subtype on survival in patients with locally advanced cervical cancer that were treated with definitive radiotherapy: adenocarcinoma/ adenosquamous carcinoma versus squamous cell carcinoma. J Gynecol Oncol 28(2): e19, 2017. PMID: 28028992. DOI: 10.3802/jgo.2017.28.e19

37 Sal V, Kahramanoglu I, Turan H, Tokgozoglu N, Bese T, Aydin $\mathrm{O}$, Demirkiran F and Arvas M: Primary signet ring cell carcinoma of the cervix: A case report and review of the literature. Int J Surg Case Rep 21: 1-5, 2016. PMID: 26874582. DOI: 10.1016/ j.ijscr.2016.02.007

38 Stolnicu S, Barsan I, Hoang L, Patel P, Chiriboga L, Terinte C, Pesci A, Aviel-Ronen S, Kiyokawa T, Alvarado-Cabrero I, Pike MC, Oliva E, Park KJ and Soslow RA: Diagnostic algorithmic proposal based on comprehensive immunohistochemical evaluation of 297 invasive endocervical adenocarcinomas. Am J Surg Pathol 42(8): 989-1000, 2018. PMID: 29851704. DOI: 10.1097/PAS.0000000000001090
39 Heeren AM, Punt S, Bleeker MC, Gaarenstroom KN, van der Velden J, Kenter GG, de Gruijl TD and Jordanova ES: Prognostic effect of different PD-L1 expression patterns in squamous cell carcinoma and adenocarcinoma of the cervix. Mod Pathol 29(7): 753-763, 2016. PMID: 27056074. DOI: 10.1038/modpathol.2016.64

40 Karpathiou G, Chauleur C, Mobarki M and Peoc'h M: The immune checkpoints CTLA-4 and PD-L1 in carcinomas of the uterine cervix. Pathol Res Pract 216(1): 152782, 2020. PMID: 31862202. DOI: 10.1016/j.prp.2019.152782

41 Rischin D, Gil-Martin M, González-Martin A, Braña I, Hou JY, Cho D, Falchook GS, Formenti S, Jabbour S, Moore K, Naing A, Papadopoulos KP, Baranda J, Fury W, Feng M, Stankevich E, Li J, Yama-Dang NA, Yoo SY, Lowy I, Mathias M and Fury MG: PD-1 blockade in recurrent or metastatic cervical cancer: Data from cemiplimab phase I expansion cohorts and characterization of PDL1 expression in cervical cancer. Gynecol Oncol 159(2): 322-328, 2020. PMID: 32917410. DOI: 10.1016/j.ygyno.2020.08.026

42 Wright AA, Howitt BE, Myers AP, Dahlberg SE, Palescandolo E, Van Hummelen P, MacConaill LE, Shoni M, Wagle N, Jones RT, Quick CM, Laury A, Katz IT, Hahn WC, Matulonis UA and Hirsch MS: Oncogenic mutations in cervical cancer: genomic differences between adenocarcinomas and squamous cell carcinomas of the cervix. Cancer 119(21): 3776-3783, 2013. PMID: 24037752. DOI: 10.1002/cncr.28288

43 Ojesina AI, Lichtenstein L, Freeman SS, Pedamallu CS, ImazRosshandler I, Pugh TJ, Cherniack AD, Ambrogio L, Cibulskis K, Bertelsen B, Romero-Cordoba S, Treviño V, Vazquez-Santillan K, Guadarrama AS, Wright AA, Rosenberg MW, Duke F, Kaplan B, Wang R, Nickerson E, Walline HM, Lawrence MS, Stewart C, Carter SL, McKenna A, Rodriguez-Sanchez IP, Espinosa-Castilla M, Woie K, Bjorge L, Wik E, Halle MK, Hoivik EA, Krakstad C, Gabiño NB, Gómez-Macías GS, Valdez-Chapa LD, GarzaRodríguez ML, Maytorena G, Vazquez J, Rodea C, Cravioto A, Cortes ML, Greulich H, Crum CP, Neuberg DS, Hidalgo-Miranda A, Escareno CR, Akslen LA, Carey TE, Vintermyr OK, Gabriel SB, Barrera-Saldaña HA, Melendez-Zajgla J, Getz G, Salvesen $\mathrm{HB}$ and Meyerson M: Landscape of genomic alterations in cervical carcinomas. Nature 506(7488): 371-375, 2014. PMID: 24390348. DOI: $10.1038 /$ nature 12881

44 Xiang L, Li J, Jiang W, Shen X, Yang W, Wu X and Yang H: Comprehensive analysis of targetable oncogenic mutations in chinese cervical cancers. Oncotarget 6(7): 4968-4975, 2015. PMID: 25669975. DOI: 10.18632/oncotarget.3212

45 Shi H, Shao Y, Lu W and Lu B: An analysis of HER2 amplification in cervical adenocarcinoma: correlation with clinical outcomes and the International Endocervical Adenocarcinoma Criteria and Classification. J Pathol Clin Res 7(1): 86-95, 2021. PMID: 33089969. DOI: $10.1002 / \mathrm{cjp} 2.184$

46 McIntyre JB, Wu JS, Craighead PS, Phan T, Köbel M, Lees-Miller SP, Ghatage P, Magliocco AM and Doll CM: PIK3CA mutational status and overall survival in patients with cervical cancer treated with radical chemoradiotherapy. Gynecol Oncol 128(3): 409-414, 2013. PMID: 23266353. DOI: 10.1016/j.ygyno.2012.12.019

47 de la Rochefordiere A, Kamal M, Floquet A, Thomas L, Petrow P, Petit T, Pop M, Fabbro M, Kerr C, Joly F, Sevin E, Maillard S, Curé H, Weber B, Brunaud C, Minsat M, Gonzague L, BertonRigaud D, Aumont M, Gladieff L, Peignaux K, Bernard V, Leroy Q, Bieche I, Margogne A, Nadan A, Fourchotte V, Diallo A, Asselain B, Plancher C, Armanet S, Beuzeboc P and Scholl SM: PIK3CA pathway mutations predictive of poor response following 
standard radiochemotherapy \pm cetuximab in cervical cancer patients. Clin Cancer Res 21(11): 2530-2537, 2015. PMID: 25724520. DOI: 10.1158/1078-0432.CCR-14-2368

48 Zammataro L, Lopez S, Bellone S, Pettinella F, Bonazzoli E, Perrone E, Zhao S, Menderes G, Altwerger G, Han C, Zeybek B, Bianchi A, Manzano A, Manara P, Cocco E, Buza N, Hui P, Wong S, Ravaggi A, Bignotti E, Romani C, Todeschini P, Zanotti L, Odicino F, Pecorelli S, Donzelli C, Ardighieri L, Angioli R, Raspagliesi F, Scambia G, Choi J, Dong W, Bilguvar K, Alexandrov LB, Silasi DA, Huang GS, Ratner E, Azodi M, Schwartz PE, Pirazzoli V, Stiegler AL, Boggon TJ, Lifton RP, Schlessinger $\mathbf{J}$ and Santin AD: Whole-exome sequencing of cervical carcinomas identifies activating ERBB2 and PIK3CA mutations as targets for combination therapy. Proc Natl Acad Sci USA 116(45): 22730-22736, 2019. PMID: 31624127. DOI: 10.1073/pnas.1911385116

49 Jiang W, Xiang L, Pei X, He T, Shen X, Wu X and Yang H: Mutational analysis of KRAS and its clinical implications in cervical cancer patients. J Gynecol Oncol 29(1): e4, 2018. PMID: 29185262. DOI: 10.3802/jgo.2018.29.e4
50 Hong DS, Fakih MG, Strickler JH, Desai J, Durm GA, Shapiro GI, Falchook GS, Price TJ, Sacher A, Denlinger CS, Bang YJ, Dy GK, Krauss JC, Kuboki Y, Kuo JC, Coveler AL, Park K, Kim TW, Barlesi F, Munster PN, Ramalingam SS, Burns TF, MericBernstam F, Henary H, Ngang J, Ngarmchamnanrith G, Kim J, Houk BE, Canon J, Lipford JR, Friberg G, Lito P, Govindan R and Li BT: KRAS ${ }^{\mathrm{G} 12 \mathrm{C}}$ inhibition with sotorasib in advanced solid tumors. N Engl J Med 383(13): 1207-1217, 2020. PMID: 32955176. DOI: 10.1056/NEJMoa1917239
Received July 5, 2021

Revised July 30, 2021

Accepted August 3, 2021 